\title{
REPETIBILIDADE DE CARACTERES DE FRUTO EM PESSEGUEIRO ${ }^{1}$
}

\author{
ROSANA GONÇALVES PIRES MATIAS 2 , CLAUDIO HORST BRUCKNER ${ }^{3}$, \\ DANIELLE FABÍOLA PEREIRA DA SILVA ${ }^{4}$, PEDRO CRESCÊNCIO SOUZA CARNEIRO ${ }^{3}$, \\ JOSÉ OSMAR DA COSTA E SILVA²
}

RESUMO - O objetivo deste trabalho foi estimar os coeficientes de repetibilidade em cultivares de pessegueiro e nectarineira e predizer o número de medições necessárias para as principais características de fruto. Em três ciclos, avaliaram-se quatorze características químicas e físicas de frutos. Para a estimativa dos coeficientes de repetibilidade, do número de medições necessárias e do coeficiente de determinação, foi utilizado o método da análise de variância (ANOVA). Determinou-se, para cada característica, o número mínimo de medições, para predizer o valor real das cultivares. Observou-se variabilidade genética entre os genótipos. As estimativas de repetibilidade foram elevadas, o que mostra a regularidade das cultivares. Para predizer o valor real dos caracteres de fruto com confiabilidade acima de $80 \%$, são necessários a realização de medições em quatro frutos e quatro anos de avaliação.

Termos para indexação: Prunus persica, número de medições, melhoramento genético.

\section{REPEATABILITY TRAITS OF PEACH FRUITS}

\begin{abstract}
The objective of this study was to estimate the coefficients of repeatability in peach and nectarine cultivars, and predict the number of required measurements for main fruit traits. Fourteen chemical and physical characteristics of fruits were measured in three cycles. The repeatability coefficients, the number of measurements required and the coefficient of determination were performed by the method of analysis of variance (ANOVA). For each trait, the minimum number of measurements to predict the actual value of the cultivars was determined. Genetic variability was observed among genotypes. Repeatability estimates were high, showing the regularity of cultivars. Measurements in four fruits and four years of evaluation are needed to predict the actual value of fruit characters with reliability above $80 \%$.
\end{abstract}

Index terms: Prunus persica, number of measurement, breeding.

1(Trabalho 255-14). Recebido em: 23-04-2014. Aceito para publicaçaõ em: 11-03-2015. Parte integrante do trabalho de doutorado em Genética e Melhoramento da primeira autora. Trabalho desenvolvido com apoio financeiro da CAPES, CNPq e FAPEMIG.

${ }^{2}$ Engenheiros-Agrônomos, DSc. Departamento de Fitotecnia, Universidade Federal de Viçosa, Av. P.H. Rolfs, s/n., 36.570-000, Viçosa, Minas Gerais, Brasil. E-mails: rosana.pires@ufv.br, joksilva7@yahoo.com.br.

${ }^{3}$ Engenheiros-Agrônomos, DSc. Professores. Departamento de Fitotecnia, Universidade Federal de Viçosa, Av. P.H. Rolfs, s/n., 36.570000, Viçosa, Minas Gerais, Brasil. E-mails: bruckner@ufv.br, carneiro@ufv.br

${ }^{4}$ Engenheira-Agrônoma, DSc. Pós-Doutoranda (Bolsista PNPD-CAPES) - Departamento de Fitotecnia, Universidade Federal de Viçosa, Av. P.H. Rolfs, s/n., 36.570-000, Viçosa, Minas Gerais, Brasil. E-mails: danieele@ufv.br 


\section{INTRODUÇÃO}

O pessegueiro, incluindo a nectarineira, pertence à família Prunus persica L. Batsch e é uma fruteira típica de clima temperado que necessita da ocorrência de temperaturas iguais ou inferiores a $7,2^{\circ} \mathrm{C}$ para sair do estado de dormência (PEREIRA et al.,2002). No Brasil, o Instituto Agronômico (IAC) e a Embrapa Clima Temperado lançaram várias cultivares com baixa exigência em frio, com necessidade inferior a 100 horas, adaptadas às regiões de clima mais ameno, tipicamente subtropical, o que permitiu o desenvolvimento da persicultura em outras regiões (MONTES et al., 2008; SOUZA et al., 2013).

A maioria das características dos frutos tem natureza quantitativa, e seu desempenho varia em decorrência de fatores ambientais, tais como temperatura do ar e índice pluviométrico. Dados de frutos coletados em apenas um ano de avaliação são geralmente insuficientes quando existe interação genótipos $\mathrm{x}$ ambientes. Contudo, em se tratando de culturas perenes, adicionar locais pode ser oneroso, e a adição de anos pode comprometer seriamente os programas de melhoramento, no sentido de prolongar demasiadamente o tempo para avaliações (SWALLOW; WEHNER, 1989).

Ao selecionar um genótipo para cultivo comercial, espera-se que sua superioridade ou bom desempenho inicial se repita ao longo de seu ciclo de vida produtiva. Tal expectativa poderá ser confirmada a partir da estimativa de coeficientes de repetibilidade para as características de interesse. A repetibilidade permite estimar o número de avaliações ou ciclos produtivos para selecionar genótipos superiores com maior eficiência e menor custo operacional. É comum fazer medições repetidas num mesmo grupo de indivíduos de espécies perenes, principalmente em coleções ou bancos de germoplasma de fruteiras, implantados sem delineamento estatístico (de LIRA JÚNIOR et al., 2014).

Estudos de repetibilidade já foram aplicados ao melhoramento de diversas culturas perenes, como cajazeira (SOARES et al., 2008; NUNES et al., 2011), guaranazeiro (NASCIMENTO FILHO et al., 2009), maracujazeiro (NEVES et al., 2010; SANTOS et al., 2010) e laranjeira-doce (NEGREIROS et al., 2008, 2014). Em alguns trabalhos com pessegueiro, foram avaliados, em estudos de repetibilidade, características químicas e físicas de fruto (ALBUQUERQUE et al., 2004), peso de fruto e duração de ciclo (DANNER et al., 2010a) e caracteres relacionados à produtividade (DELLA BRUNA et al., 2012).

Os caracteres de interesse no melhoramen- to do pessegueiro expressam-se mais de uma vez em cada indivíduo, gerando dados de colheitas ou medidas repetidas. Assim, o objetivo deste trabalho foi estimar os coeficientes de repetibilidade em cultivares de pessegueiro e de nectarineira e predizer o número de frutos e de anos necessários para avaliação de genótipos quanto às principais características de fruto.

\section{MATERIAL E MÉTODOS}

O estudo foi desenvolvido durante os ciclos produtivos de 2011, 2012 e 2013, com 28 cultivares de pessegueiro e duas cultivares de nectarineira. Essas cultivares pertencem à coleção pessegueiro e nectarineira da Universidade Federal de Viçosa, Viçosa-MG (2045'S e 42 $51^{\prime}$ 'O; $649 \mathrm{~m}$ de altitude). O plantio foi realizado em outubro de 2008 , utilizando-se como porta-enxerto do pessegueiro 'Okinawa', em espaçamento de 5,0 metros (m) entre linhas e $3,5 \mathrm{~m}$ entre plantas. Cada cultivar está representada por três plantas dispostas lado a lado. Foram realizados todos os tratos culturais normalmente recomendados para a cultura, como adubação, podas, quebra de dormência, raleio de frutos e irrigação.

Em cada ano, foram coletados 30 frutos de três plantas, de cada cultivar, e avaliados a massa do fruto (MF) (g), os diâmetros sutural (DS), equatorial (DE) e polar (DP) (mm); a firmeza da polpa (FIR), em Newton $(\mathrm{N})$; o teor de sólidos solúveis dos frutos (SS) ( ${ }^{\circ}$ Brix); a acidez titulável (AT) (\% de ácido málico); a razão entre o teor de sólidos solúveis da polpa e a acidez titulável (SS/AT); o teor de ácido ascórbico da polpa (AA) (mg de ácido ascórbico $100 \mathrm{~g}^{-1}$ de polpa) e o teor de carotenoides (CT) (mg $100 \mathrm{~g}^{-1}$ de polpa). As estimativas do coeficiente de repetibilidade (r), do número de medições necessárias $\left(\eta_{0}\right)$ para uma predição adequada e do coeficiente de determinação $\left(\mathrm{R}^{2}\right)$ para o número de medições realizadas foram obtidas por meio do programa GENES (CRUZ, 2013). Para isso, seguiu-se metodologia descrita em Cruz et al. (2012), sendo utilizado o método da análise de variância (ANOVA).

Para a determinação do número de frutos foi adotado o modelo com um fator de variação a seguir: $Y_{i j}: \mu+g_{i}+\varepsilon_{i j}$, em que:

$Y_{i j}$ : observação referente à i-ésima cultivar $(i=1,2, \ldots, p)$ na j-ésima medição $(j=1,2, \ldots, \eta)$; $\mu$ : média geral; $\mathrm{g}_{\mathrm{i}}$ : efeito aleatório da i-ésima cultivar sob a influência do ambiente permanente $(i=1,2, \ldots, p)$; $\varepsilon_{\mathrm{ij}}$ : efeito do ambiente temporário associado à j-ésima medição na i-ésima cultivar. 
Para a determinação do número de anos, considerou-se o seguinte modelo com dois fatores de variação (cultivar e ano):

$Y_{i j}: \mu+g_{i}+a_{j}+\varepsilon_{i j}$, em que:

$\mathrm{Y}_{\mathrm{ij}}$ : observação referente à i-ésima cultivar (i $=1,2, \ldots, p)$ no j-ésimo ano $(\mathrm{j}=1,2, \ldots, \eta)$;

$\mu$ : média geral;

$\mathrm{g}_{\mathrm{i}}$ : efeito aleatório da i-ésima cultivar sob a influência do ambiente permanente $(i=1,2, \ldots, p)$;

$a_{j}$ : efeito fixo do ambiente temporário no j-ésimo ano $(\mathrm{j}=1,2, \ldots, \eta)$;

$\varepsilon_{\mathrm{ij}}$ : erro experimental estabelecido pelo efeito do ambiente temporário no j-ésimo ano da i-ésima cultivar.

O coeficiente de repetibilidade foi dado por:

$\hat{\mathrm{r}}=\hat{\rho}=\frac{\operatorname{Cov}\left(Y_{i j}, Y_{i j^{\prime}}\right)}{\sqrt{\hat{V}\left(Y_{i j}\right) \hat{V}\left(Y_{i j^{\prime}}\right)}}=\frac{\hat{\sigma}_{g}^{2}}{\hat{\sigma}_{Y}^{2}}=\frac{\hat{\sigma}_{g}^{2}}{\hat{\sigma}^{2}+\hat{\sigma}_{g}^{2}}$, em que:

$\mathrm{Y}_{\mathrm{ij}}$ e $\mathrm{Y}_{\mathrm{ij}}$, são as diferentes medidas, realizadas num mesmo indivíduo.

Uma vez estimado o coeficiente de repetibilidade $(\hat{\mathrm{r}})$, a estimativa do número de medições $\left(\eta_{0}\right)$ necessárias para se predizer o valor real dos indivíduos com o valor de determinação genotípica $\left(\mathrm{R}^{2}\right)$ desejado foi obtida pela expressão:

$$
\eta_{0}=\frac{R^{2}(1-\hat{r})}{\left(1-R^{2}\right) \hat{r}}
$$

O coeficiente de determinação genotípica $\left(\mathrm{R}^{2}\right)$, que representa a porcentagem de certeza da predição do valor real dos indivíduos selecionados com base em $\eta$ medições foi obtido pela equação:

$$
\mathrm{R}^{2}=\frac{\eta \hat{\mathrm{r}}}{1+\hat{\mathrm{r}}(\eta-1)}
$$

\section{RESULTADOS E DISCUSSÃO}

De acordo com os resultados da análise de variância para todas as características, verificaram-se diferenças significativas entre as cultivares estudadas, evidenciando que o componente de variância genético confundido com os efeitos permanentes do ambiente é significativo, fato esse relevante nos programas de melhoramento visando à otimização do número de medições (Tabela 1).

As estimativas dos coeficientes de repetibilidade $(r)$ e de determinação $\left(R^{2}\right)$ com relação ao número mínimo de frutos, para as avaliações realizadas, encontram-se na Tabela 2 . As características massa de fruto (MF), diâmetro sutural (DS), diâmetro equatorial (DE), diâmetro polar (DP) e firmeza da polpa (FIR) apresentaram coeficientes de repetibilidade entre 0,54 e 0,73 e coeficientes de determinação acima de 90\%. Estes resultados foram semelhantes aos obtidos por Albuquerque et al. (2004) em pessegueiro e nectarineira, em dois anos de avaliação.

Os coeficientes de repetibilidade para teor de sólidos solúveis (SS) foram de 0,66, 0,77 e 0,65, nos anos de 2011, 2012 e 2013, respectivamente. Esses valores assemelham-se ao relatado por Danner et al. (2010b), obtido a partir da medição de 20 frutos de araçazeiro $(0,65)$, entretanto superiores ao encontrado por Negreiros et al. (2014), obtido para laranja-doce em cinco anos de avaliação $(0,31)$.

Conforme Resende (2002), as estimativas do coeficiente de repetibilidade (r) são classificadas como baixas quando $r \leq 0,30$, médias quando $0,30<\mathrm{r}$ $<0,60$ e altas quando $r \geq 0,60$. Assim, as estimativas encontradas no presente trabalho foram altas nos três anos de avaliação, exceto para firmeza, em 2011 e 2013 (0,59 e 0,54, respectivamente). Coeficientes de repetibilidade de alta magnitude refletem a estabilidade das cultivares, a acurácia da avaliação dos valores fenotípicos e o forte controle genético (CRUZ et al., 2012), o que facilita os trabalhos de melhoramento.

As características teor de carotenoides (CT) e acidez titulável (AT) apresentaram maior acurácia nos três anos de avaliações, com estimativas dos coeficientes de repetibilidade variando de 0,78 a 0,89 , com coeficientes de determinação $\left(\mathrm{R}^{2}\right)$ entre 99,07 e 99,60\%, indicando maior precisão na predição do valor real desses caracteres, no pessegueiro e nectarineira. Em trabalhos realizados com bacurizeiro (SOUZA et al., 2001) e aceroleira (LOPES et al., 2001), caracteres de frutos como comprimento, diâmetro, acidez titulável e vitamina $\mathrm{C}$ também apresentaram coeficientes de repetibilidade com elevadas magnitudes $(r>0,70)$.

Para as características massa de fruto, diâmetro sutural, diâmetro equatorial, diâmetro polar e firmeza, são necessários três e oito frutos, com coeficientes de determinação de 80 e $90 \%$, respectivamente (Tabela 3 ), para predizer o valor real das cultivares, valores semelhantes aos encontrados por Albuquerque et al. (2004), que concluíram que a seleção baseada em nove frutos leva a uma precisão de $90 \%$ dos valores fenotípicos das referidas características.

Com relação aos teores de ácido ascórbico e de carotenoides, características que exigem maior gasto de tempo e de reagentes para sua quantificação, 
verifica-se que, com apenas dois e um fruto, respectivamente, é possível predizer o valor real das cultivares com $80 \%$ de confiabilidade. Esses dados são muito importantes, uma vez que possibilita a economia de tempo e de recurso na seleção de indivíduos superiores.

A avaliação de quatro frutos é suficiente para predizer o valor real de todos os caracteres, com $80 \%$ de confiabilidade. Para seleção de genótipos com $90 \%$ de determinação do valor real, o número de frutos determinado como necessário variou de 2 a 8 , entre as 10 características e nos três anos de estudo (Tabela 3), tamanho amostral inferior ao utilizado no presente trabalho.

$\mathrm{Na}$ Tabela 4, encontram-se os coeficientes de repetibilidade (r) e de determinação $\left(\mathrm{R}^{2}\right)$ para as avaliações realizadas e o número de anos $\left(\eta_{0}\right)$ necessários para predizer o valor real dos indivíduos com 80 e $90 \%$ de acurácia. Verifica-se que todas as características apresentaram coeficientes de repetibilidade considerados altos $(r>0,60)$.

Para massa de fruto, obteve-se o coeficiente de repetibilidade e de determinação de 0,71 e $87,82 \%$, respectivamente, valores semelhantes aos encontrados por Danner et al. (2010a) para pessegueiro, em cinco anos de avaliação pelo método da ANOVA (0,72 e 92,70\%). O teor de sólidos solúveis apresentou valores de $\mathrm{r}$ e $\mathrm{R}^{2}$ de 0,83 e $93,49 \%$, respectivamente. Em araçá, os valores de $\mathrm{r}$ e $\mathrm{R}^{2}$ foram de 0,65 e $82,91 \%$ e, em pitanga, de 0,37 e $69,79 \%$, obtidos pelo método da ANOVA, em cinco anos de avaliação (DANNER et al., 2010b).

Observou-se que, para as características diâmetro polar, teor de sólidos solúveis, acidez titulável, teor de ácido ascórbico e teor de carotenoides, apenas um ano de avaliação já é suficiente para se ter uma acurácia de $80 \%$ na predição do valor real dos indivíduos. Para massa de fruto, diâmetro sutural, diâmetro equatorial, firmeza e relação SS/AT, dois anos são necessários para se ter $80 \%$ de confiabilidade. Para seleção de genótipos com $90 \%$ de determinação do valor real, o número de anos determinado como necessário variou, entre as dez características, de 2 a 5 (Tabela 4). Maiores níveis de precisão podem requerer número de medições muito maiores e aumentar os custos (OLIVEIRA; FERNANDES, 2001), o que dificulta o processo de avaliação.

Com base nos resultados obtidos e visando a reduzir custos e a aumentar a eficiência da seleção, recomenda-se realizar as avaliações de frutos, selecionando, já no primeiro ano, genótipos superiores quanto às características que necessitam de apenas um ano de avaliação, e assim por diante.
Com isso, infere-se ser possível reduzir o número de plantas em avaliação nas fases iniciais do processo e efetuar as avaliações que necessitam de maior repetição em menor número de plantas, com a 


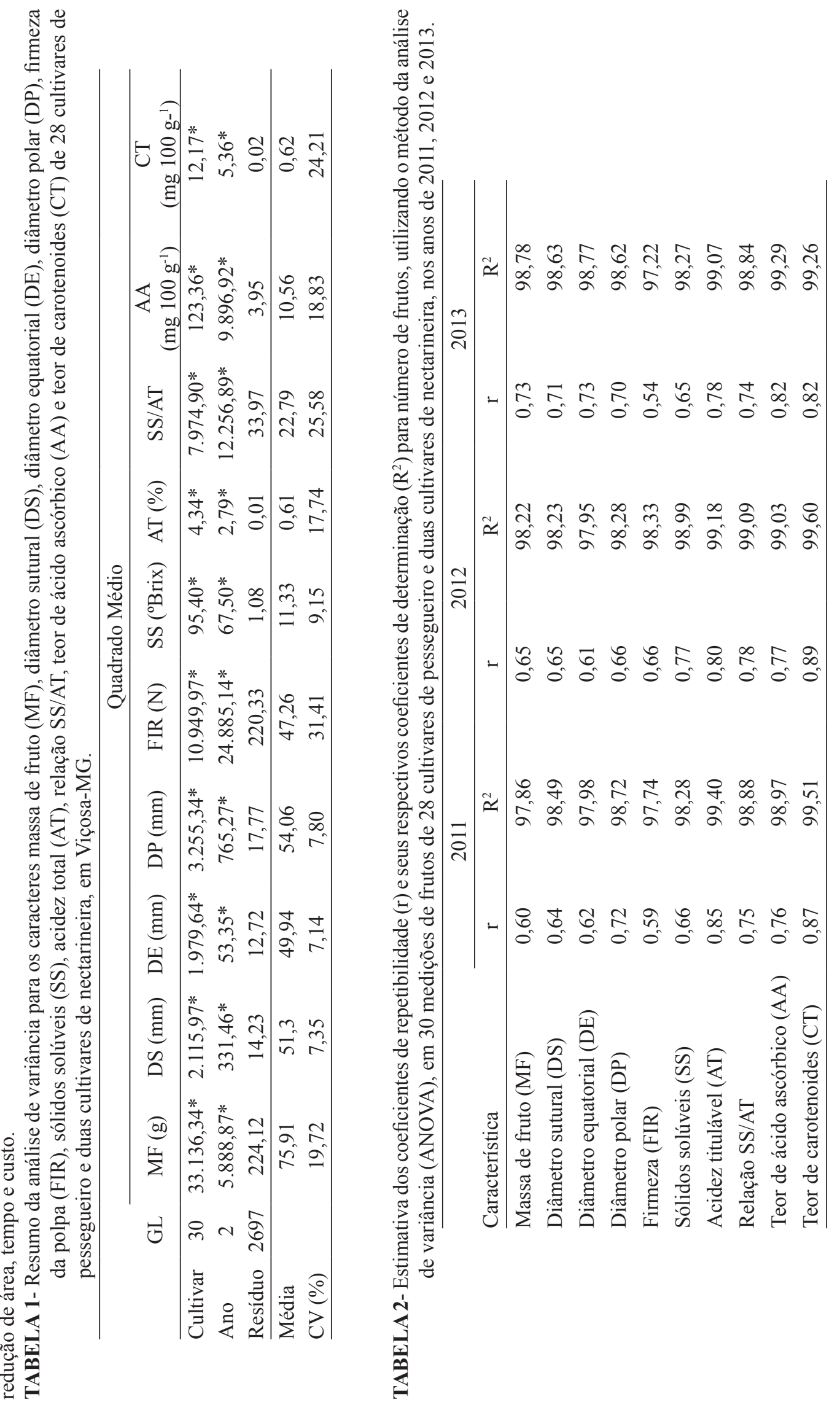




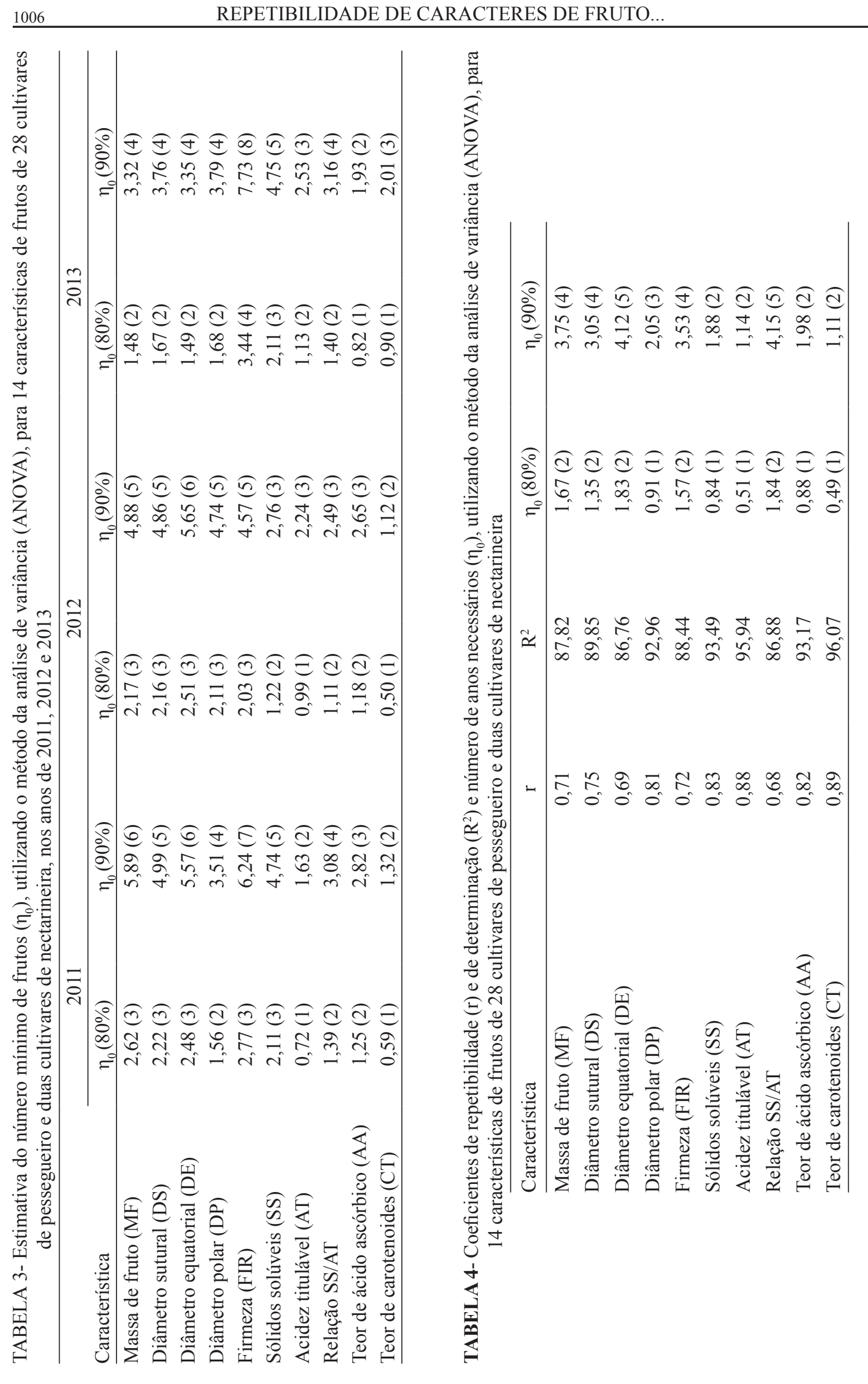

Rev. Bras. Frutic., Jaboticabal - SP, v. 37, n. 4, p. 1001-1008, Dezembro 2015 


\section{CONCLUSÕES}

Todos os caracteres apresentaram estimativas de coeficientes de repetibilidade consideradas de média a alta magnitude.

Quatro frutos são suficientes para predizer o valor real de cultivares de pessegueiro e nectarineira com $80 \%$ de acurácia, com relação à massa de fruto, diâmetros sutural, equatorial e polar, firmeza, teor de sólidos solúveis (SS), acidez titulável (AT), relação SS/AT, teores de ácido ascórbico e de carotenoides.

Com quatro anos de avaliação, é possível predizer o valor real dos indivíduos com $80 \%$ de acurácia, com relação às 14 características de fruto avaliadas no presente trabalho.

\section{AGRADECIMENTOS}

Ao CNPq (Conselho Nacional de Desenvolvimento Científico e Tecnológico), CAPES (Coordenação de Aperfeiçoamento de Pessoal de Nível Superior) e FAPEMIG (Fundação de Amparo à Pesquisa do Estado de Minas Gerais), pelo apoio financeiro.

\section{REFERÊNCIAS}

ALBUQUERQUE, A.S.; BRUCKNER, C.H.; CRUZ, C.D.; SALOMÃO, L.C.C.; NEVES, J.C.L. Repeatability and correlations among peach physical traits. Crop Breeding and Applied Biotechnology, Londrina, v.4, p.441-445, 2004.

CRUZ, C.D. GENES - a software package for analysis in experimental statistics and quantitative genetics. Acta Scientiarum. Agronomy, Maringá, v.35, p.271-276, 2013.

CRUZ, C.D.; REGAZZI, A.J.; CARNEIRO, P.C.S. Modelos biométricos aplicados ao melhoramento genético. 4.ed. Viçosa: Editora UFV, 2012. 514p.

DANNER, M.A.; RASEIRA, M.C.B.; SASSO, S.A.Z.; CITADIN, I.; SCARIOT, S. Repetibilidade de peso de fruto e de duração de ciclo em ameixeira e pessegueiro. Pesquisa Agropecuária Brasileira, Brasília, v.45, n.8, p.872-878, 2010a.
DANNER, M.A.; RASEIRA, M.C.B.; SASSO, S.A.Z.; CITADIN, I.; SCARIOT, S. Repetibilidade de caracteres de fruto em araçazeiro e pitangueira. Ciência Rural, Santa Maria, v.40, n.10, p.20862091, 2010b. Disponível em: <http://www. scielo.br/scielo.php?script $=$ sci arttext\&pid $=$ S0103-84782010001000006 $>$. Acesso em: 21 ago. 2014. doi: 10.1590/S0103-84782010005000163.

DELLA BRUNA, E.; MORETO, A.L.; DALBÓ, M.A. Uso do coeficiente de repetibilidade na seleção de clones de pessegueiro para o litoral sul de Santa Catarina, Revista Brasileira de Fruticultura, Jaboticabal, v.34, n.1, p.206-215, 2012. Disponível em: $\leq$ http://www.scielo.br/scielo. php?pid=S0100-29452012000100028\&script $=$ sci arttext>. Acesso em: 02 set. 2014. doi: 10.1590/ S0100-29452012000100028.

LIRA JÚNIOR, J.S.; BEZERRA, J.E.F.; MOURA, J.R.M.; SANTOS, V.F. Repetibilidade da produção, número e peso de fruto em cirigueleira (Spondias purpúrea L.). Revista Brasileira de Fruticultura, Jaboticabal, v.36, n.1, p.214-220, 2014. Disponível em: $\leq$ http://www.scielo.br/scielo.php?script $=$ sci arttext\&pid $=$ S0100-29452014000100025\&lng $=p t$ \&nrm $=\mathrm{iso} \& \mathrm{t} \operatorname{lng}=\mathrm{pt}>$. Acesso em: 01 set. 2014. doi: 10.1590/0100-2945-294/13.

LOPES, R.; BRUCKNER, C.H.; CRUZ, D.C.; LOPES, M.T.G.; FREITAS, G.B. Repetibilidade de características do fruto de aceroleira. Pesquisa Agropecuária Brasileira, Brasília, v.36, n.3, p.507513, 2001.

MONTES, S.M.N.M.; BOLIANI, A.C.; RAGA, A.; SANTOS, P.C.;CORRÊA, L.S.; FERRARI, J.T. Características produtivas, físicas e químicas de frutos de cultivares de pessegueiros sobre dois porta-enxertos no oeste do estado de São Paulo. Revista Brasileira de Fruticultura, Jaboticabal, v.30, n.4, p.1065-1070, 2008. Disponível em: $\leq$ http:// www.scielo.br/scielo.php?script $=$ sci arttext\&pid $=\mathrm{S} 0100-29452008000400037>$. Acesso em: 21 ago. 2014. doi: 10.1590/S0100-29452008000400037. 
NASCIMENTO FILHO, F.J. do; ATROCH, A.L.; CRUZ, C.D.; CARNEIRO, P.C.S. Repetibilidade da produção de sementes em clones de guaraná. Pesquisa Agropecuária Brasileira, Brasília, v.44, n.6, p.605-612, 2009. Disponível em: $\leq$ http://www.scielo.br/scielo.php?pid=S0100$204 \times 2009000600009 \&$ script $=$ sci arttext $>$. Acesso em: 21 ago. 2014. doi: 10.1590/S0100204X2009000600009.

NEGREIROS, J.R. da S.; NETO, R. de C.A.; MIQUELONI, D.P.; LESSA, L.S. Estimativas de repetibilidade para caracteres de qualidade de frutos de laranjeira-doce. Pesquisa Agropecuária Brasileira, Brasília, v.49, n.1, p.40-48, 2014.

NEGREIROS, J.R. da S.; SARAIVA, L.L.; OLIVEIRA, T.K.; ÁLVARES, V.S.; RONCATTO, G. Estimativas de repetibilidade de caracteres de produção em laranjeiras-doces no Acre. Pesquisa Agropecuária Brasileira, Brasília, v.43, n.12, p.1763-1768, 2008.

NEVES, L.G.; BRUCKNER, C.H.; CRUZ, C.D.; BARELLI, M.A.A. Avaliação da repetibilidade no melhoramento de famílias de maracujazeiro. Revista Ceres, Viçosa, MG, v.57, n.4, p.480-485, 2010. Disponível em: $\leq$ http://www.scielo.br/scielo. php?pid=S0034-737X2010000400007\&script $=$ sci arttext>. Acesso em: 21 ago. 2014. doi: 10.1590/ S0034-737X2010000400007.

NUNES, J.A.R.; SANTANA, F.F.; GOMES, R.L.F.; LOPES, A.C.A.; PEREIRA, M.M.G.; SOARES, E.B. Stratified mass selection of promising Spondias mombin clones in a commercial crop. Crop Breeding and Applied Biotechnology, Londrina, v.11, p.141148, 2011.

OLIVEIRA, M.S.P.; FERNANDES, G.L.C. Repetibilidade de caracteres do cacho de açaizeiro nas condições de Belém-PA. Revista Brasileira de Fruticultura, Jaboticabal, v.23, n.3, p.613-616, 2001.

PEREIRA, F.M.; NACHTIGAL, J.C.; ROBERTO, S.R. Tecnologia para a cultura do pessegueiro em regiões tropicais e subtropicais. Jaboticabal: FUNEP, 2002. 61p.
RESENDE, M. D. V. de. Genética biométrica e estatística no melhoramento de plantas perenes. 21. ed. Brasilia: Embrapa Informação Tecnológica: Colombo: Embrapa Florestas, 2002. 975 p.

SANTOS, C.E.M.; BRUCKNER, C.H.; CRUZ, C.D.; SIQUEIRA, D.L.; PIMENTEL, L.D.; ROSADO, L.D.S. Repetibilidade em características do fruto do maracujazeiro. Revista Ceres, Viçosa, MG, v.57, n.3, p.343-350, 2010. Disponível em: $\leq$ http://www.scielo.br/scielo. php?pid=S0034-737X2010000300009\&script $=$ sci abstract\&tlng $=$ pt $>$. Acesso em: 21 ago. 2014. doi: 10.1590/S0034-737X2010000300009.

SOARES, E.B.; GOMES, R.L.F.; CAMPELO, J.E.G.; LOPES, Â.C. de A.; MATOS FILHO, C.H.A. Repetibilidade e correlações entre caracteres morfo-agronômicos de cajazeira. Ciência e Agrotecnologia, Lavras, v.32, n.6, p.1851-1857, 2008. Disponível em: < http:// www.scielo.br/scielo.php?script=sci arttext\&pid $=$ S1413-70542008000600025>. Acesso em: 21 ago. 2014. doi: 10.1590/S1413-70542008000600025.

SOUZA, F.B.M.; ALVARENGA, A.A.; PIO, R.; GONÇALVES. E.D.; PATTO, L.S. Produção e qualidade dos frutos de cultivares e seleções de pessegueiro na Serra da Mantiqueira. Bragantia, Campinas, v.72, n.2, p.133-139, 2013. Disponível em: $\leq$ http://www.scielo.br/scielo. php?script=sci arttext\&pid $=$ S0006-87052013000200004\&lng $=$ pt\&

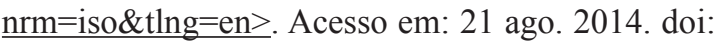
$10.1590 / \mathrm{S} 0006-87052013005000024$.

SOUZA, V.A.B.;ARAÚJO,E.C.E.; VASCONCELOS, L.F.L.; LIMA, P.S.C. Variabilidade de características físicas e químicas de frutos de germoplasma de bacuri da região meio-norte do Brasil. Revista Brasileira de Fruticultura, Jaboticabal, v.23, n.3, p.677-683, 2001.

SWALLOW, W.H.; WEHNER, T. Optimum allocation of plots to years, seasons, locations, and replications, and its application to once-over-harvest cucumber trials. Euphytica, Dordrecht, v.43, p.5968, 1989. 